
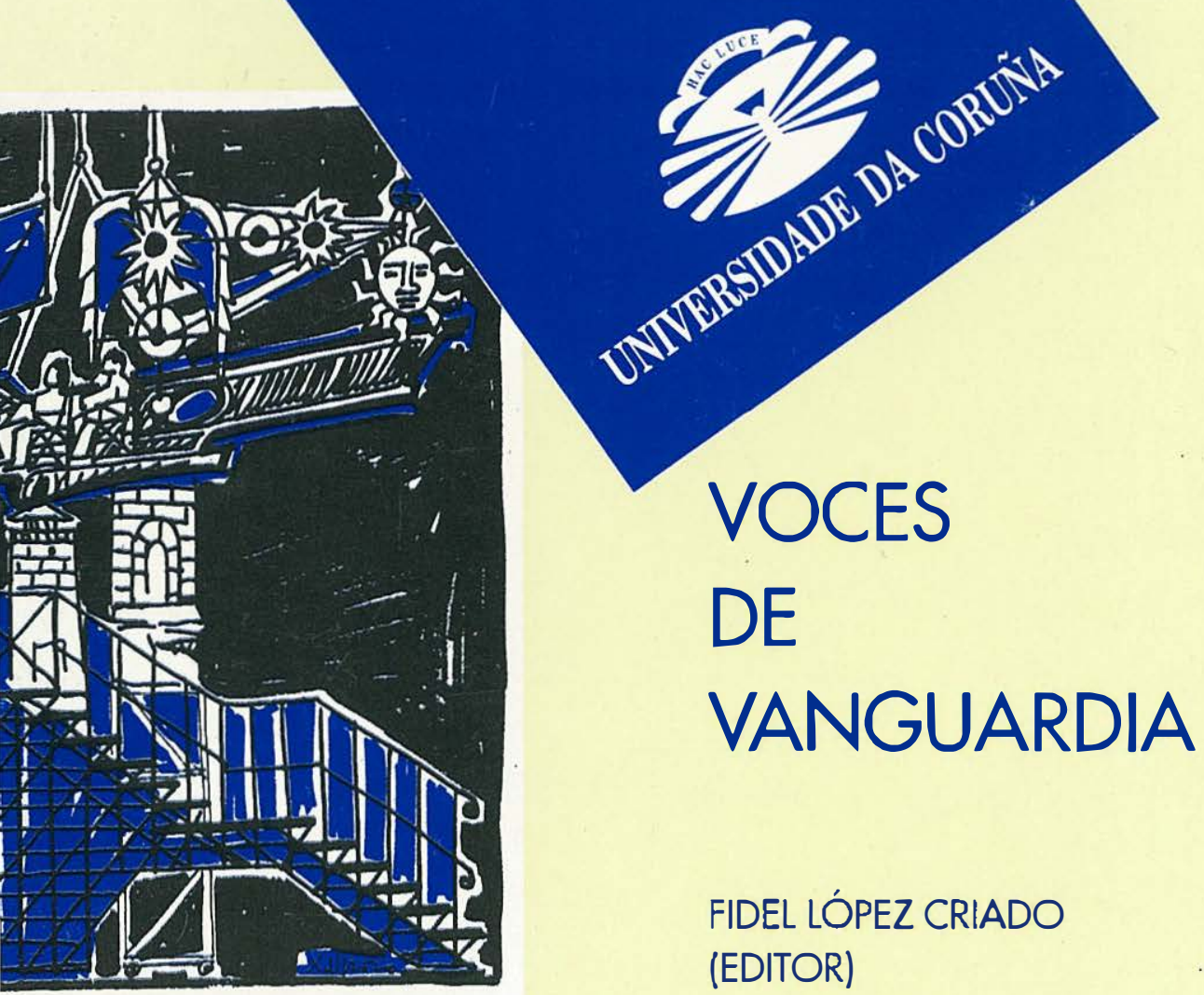

FIDEL LÓPEZ CRIADO (EDITOR)

COLECCION: CURSOS, CONGRESOS E SIMPOSIOS 


\section{VOCES DE VANGUARDIA}

Fidel López Criado (Editor)

Actas del Ciclo de Conferencias "El nuevo siglo: el hombre y el arte en las vanguardias", celebrado en la Universidad de A Coruña, en octubre de 1994, bajo la dirección del profesor Fidel López Criado. 
DOI: https://doi.org/10.17979/spudc. 9788497497725

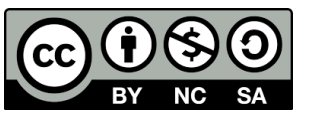

Esta obra se publica en su formato electrónico bajo una licencia

Creative Commons Atribución-NoComercial-CompartirIgual 4.0 Internacional (CC BY-NC-SA 4.0)

COLECCIÓN: CURSOS,

CONGRESOS E SIMPOSIOS $\mathbf{1 8}$

\section{VOCES DE VANGUARDIA}

EDICIÓN:

UNIVERSIDADE DA CORUÑA

SERVICIO DE PUBLICACIÓNS

(C) DE ESTA EDICIÓN

\section{UNIVERSIDADE DA CORUÑA}

Imprime: ImpañA MENoo, s.L.

Depósito Legal: C-996/1995

Depósito Legal: C-560/2020 (electrónico)

I.S.B.N.: 84-88301-01-4

I.S.B.N.: 978-84-9749-772-5 (electrónico) 


\section{INDICE}

I. INTRODUCCION

Alfredo Rodríguez López-Vázquez. ............................................... 7

II. RUPTURA Y NOVACION EN EL TEATRO VANGUARDISTA

DE RAMON GOMEZ DE LA SERNA (1909-1912).

Fidel López Criado

III. LA INFILTRACION DEL CUBISMO EN EL TEATRO JOVEN DE RAMON GOMEZ DE LA SERNA.

Alfredo Martínez Expósito

IV. LUGAR Y METAFORA: PERSPECTIVA DE METROPOLIS DESDE RAMON GOMEZ DE LA SERNA.

José Enrique Serrano Asenjo

V. LOS FRUTOS DE LA VANGUARDIA HISTORICA.

José Luis Bernal.

VI. PRESAGIOS DE TORMENTA: LA REVISTA

ATLANTICO (1929-1933)

José Carlos Mainer.

VII. ANTONIO MARTINEZ SARRION EN LA CRISIS DE LA VANGUARDIA: TEATRO DE OPERACIONES Y PAUTAS PARA CONJURADOS.

Francisco J. Díaz de Castro y Almudena del Olmo Iturriarte. 
La idea de este volumen, su razón de ser textual, surge del consenso fraguado en torno al ciclo de conferencias, "El nuevo siglo: el hombre y el arte en las vanguardias", celebrado en la Univesidad de A Coruña en octubre de 1994, donde algunos de los trabajos aquí recogidos (Bernal, Mainer, Díaz de Castro) no sólo ven la luz por primera vez, sino que sirven igualmente para alumbrar la urgente e imperiosa necesidad de revisar y ahondar críticamente la significación y trascendencia literaria de las vanguardias (las de aquel ayer histórico de principios de siglo y todas las que, desde entonces, se vislumbran con cada nuevo amanecer de la creatividad humana). Consecuentemente, los trabajos recogidos en esta edición dirigen su atención hacia unas parcelas de estudio que, ensombrecidas por el desconocimiento y la desatención crítica, han permanecido largo tiempo como el lado oculto de nuestras letras. No obstante, gracias al inestimable apoyo de tan notables estudiosos como los que aquí nos ofrecen generosamente el esfuerzo de su labor investigadora, hoy es posible hacer llegar el eco de unas Voces de Vanguardia que, en su conjunto, han contribuido decididamente a esa corriente de "novación" ético-estética de nuestras letras que, a su vez, hace posible el desarrollo cultural, social y político de nuestros pueblos. En este sentido, espero que este volumen sirva para estimular y potenciar un diálogo crítico cuya importancia y relevancia histórico-literaria parece verse reflejada, con particular contundencia y nitidez, por el creciente número de congresos y publicaciones que han surgido estos últimos años en torno a la producción literaria de las vanguardias españolas.

Fidel López Criado 


\title{
Lugar y metáfora: Perspectiva de Metrópolis desde Ramón Gómez de la Serna
}

\author{
José Enrique Serrano Asenjo
}

DOI: https://doi.org/10.17979/spudc.9788497497725.081

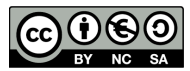

"It is not surprising that Modernism, the product of cities, should be so impelled to recreate the image of cities. One of the greatest Modernists, in this respect, is Charlie Chaplin, who has so brilliantly rendered the metropolis in all its frustrations and incongruities."118 Lo mismo podría decirse de Fritz Lang o, pongamos por caso, Ramón Gómez de la Serna. En efecto, si tomamos como punto de referencia el género narrativo, debe tenerse en consideración que, según Ioana Zlotescu, nuestro escritor configura la realidad de sus novelas sobre la nueva realidad de la urbe contemporánea. ${ }^{119}$ Por otra parte, Rey Briones destaca la doble faz de dicho componente espacial en sus relatos extensos, que comporta laberinto y caos, incongruencia y contradicción, mas también excitación, sorpresa y espectáculo. ${ }^{120}$ Aquí se insistirá en la naturaleza dual de las ciudades ramonianas pero con otra perspectiva, a

118 Levin, Harry. "What was Modernism?". Refractions. Essays in Comparative Literature, Nueva York: Oxford U. P., 1968; 271-95, y 291.

119 "Ciudades para una época”, Revista de Occidente, 80 (1988), 82-92; 87. Vid. también Camón Aznar, J. Ramón Gómez de la Serna en sus obras. Madrid: Espasa-Calpe, 1972; 74-5; y Urrutia, J. El novecentismo y la renovación vanguardista. Madrid: Cincel, 1980, 54.

${ }^{120}$ Rey Briones, A del. La novela de Ramón Gómez de la Serna. Madrid: Verbum, 1992, 56. 
saber, al deambular por la geografía urbana del escritor vamos a descubrir lugares complejos como consta en el retrato recién aludido, pero en no menor medida hallaremos metáforas sobre la naturaleza del mundo con sus añagazas, incitaciones y, sobre todo, con su significado global. ${ }^{121}$

Antes de pasar a varias narraciones que nos permitirán comprobar el funcionamiento del factor que nos interesa, conviene traer a colación un curioso ensayo sobre el particular. Lleva por título "La Idea y la Ciudad", su autor es el hombre de la Torre de Marfil, contiene insistentes alusiones políticas, a veces no demasiado veladas, y a pesar de no dar cuenta cabal del papel de la ciudad en las novelas de Gómez de la Serna, al menos revela la trascendencia que el creador le otorgó. Ramón pretende elaborar una suerte de "doctrina de la ciudad", sólo que a su. modo, es decir, con técnica greguerística, que disuelve el discurso mediante una sistemática fragmentación, y "con desenvoltura lírica y generosa". ${ }^{22}$

Tal empresa le da pie para abordar sus obsesiones más arraigadas: "El armisticio íntimo por la ciudad debe ser incondicional porque en ella está el molde laberíntico de la justificación de vivir" (p. 112). En el ensayo es posible documentar ampliamente una actitud de autodefensa por parte del literato. A mi ver, Gómez de la Serna encarna como pocos escritores españoles la figura del individuo inmerso en la modernidad, hostigado por ella, que busca su lugar en un contexto de pérdida del sentido de la vida. Más claro que en la cita anterior, esto se aprecia cuando alude a "aquellos sitios en que las ciudades tienen un instinto ciudadano que las hace salvarse de todo" (p. 100). Curiosamente Gómez de la Serna posee una obra de obvias implicaciones metafísicas en la que un asidero crucial son las cosas: "No hay más que las cosas y la Gran Cosa que es el Dios que engloba todas las cosas. La verdadera Idea resulta por eso el respeto a las cosas y como flor de todas las cosas, como la única eficiencia de la civilización: la Ciudad" (p. 98). ${ }^{123}$ A la postre, esta encrucijada en que cristalizan los aspectos más significativos de la percepción ramoniana de la realidad basa su importancia en la alta dosis de con-

121 Cfr. M. Bradbury, "The Cities of Modernism”, en M. Bradbury y J. McFarlane. Modernism 1890-1930. Londres: Penguin, 1991 [1 ${ }^{\text {a }}$ ed. en 1976], 96-104; 97: "The pull and push of the city, its attraction and repulsion, have provided themes and attitudes that run deep in literature, where the city has become metaphor rather than place."

122 Lo cursi y otros ensayos, BB. AA., Ed. Sudamericana, 1943, 112. Todas las citas se realizan por esta edición.

123 Cfr. H. von Hofmannsthal, Carta de Lord Chandos (Pr. de C. Magris), Murcia: Colegio Oficial de Aparejadores y Arquitectos Técnicos - Librería Yerba - Consejería de Cultura del Consejo Regional, 1981. 
ciencia que conlleva, pues no en vano "Lejos de la ciudad, o arrasada la ciudad, no se vería la injusticia de morir, la hermosa riqueza de no tener más remedio" (p. 108). Dicho de otra forma, el ámbito metropolitano permite al hombre hacerse cargo de su condición plenamente, lucidez que es condición y característica de las novelas del autor de Entrando en fuego.

Cinelandia resulta "la más variada y estrambótica de las ciudades". ${ }^{124} \mathrm{Al}$ acercarse al mundo del cinematógrafo, Gómez de la Serna como primera providencia describe "La gran urbe". Brian Morris, en la más brillante indagación crítica sobre esta novela, repara en que la pintura de la misma excluye toda coherencia y autenticidad, a la vez que se apoya en una multitud de componentes heterogéneos. ${ }^{125}$ Sirva a modo de confirmación el pasaje siguiente: "El aspecto de Cinelandia, desde lejos, tenía algo de Constantinopla, mezclada de Tokio, con algo de Florencia y con bastante de Nueva York" (p. 7). Y es que estamos ante el pórtico de la ciudad cosmopolita, una ciudad de ciudades, o para ser más precisos, una suma de fragmentos de ciudades. En ella la existencia no parece muy fácil: "El paseo por las calles de la población tenía algo de pesadilla, y el que lo realizaba era como un viajero circunvalador que lograba dar la vuelta al mundo en una hora" ( $p$. 8); o si lo concretamos en el héroe parcial de la historia: "Jacobo Estruk perdía la cabeza en la variedad de los sitios" (p. 10). Nos hallamos ante una mera ficción que sustituye, por su semejanza, al orbe caótico en que no sólo se desorienta Estruk, sino especialmente Ramón. Se trata, pues, de la ciudad metafórica que alcanza su máxima expresión algo más de veinte años después.

En El hombre perdido encontramos un eco de Cinelandia, porque el Luna Park permite "la vuelta al mundo en cinco minutos". ${ }^{126}$ El significado de la ciudad surge hipertrofiado en ese recinto, de manera que si Metrópolis suponía un trasunto del mundo, con el Luna Park esto sucede en mayor medida, quizá por tratarse de un espacio más reducido. Sea como fuere, "Es el sitio en que somos emigrantes aun en nuestra propia patria" (p. 67). El hom-

124 Cinelandia. Valencia: Sempere, 1923, 9. Las citas de esta obra envían a esta edición.

125 “Cinelandia: Ramón in Shadowland”, en N. Dennis ed., Studies on Ramón Gómez de la Serna, Ottawa: Dovehouse, 1988, 153-71; 157. Vid. también D. Henn, "La gran ciudad falsa: Cinelandia ", Cuadernos Hispanoamericanos, 350 (1979), 377-87; 386-7: "Este mundo, con sus tipos, actitudes y visiones es, para Ramón “ 'la nueva Gomorra y Sodoma' del siglo veinte y, a la vez, posiblemente toda ciudad del porvenir”.

${ }^{126}$ El hombre perdido (1947). Madrid: Espasa-Calpe, 1962; 72. Las páginas tras los fragmentos de la novela envían a esta edición. 
bre coetáneo por definición es "emigrante", desplazado, uno que no está en el espacio que le corresponde, en buena medida por todo ello, "ciego": "los ciudadanos de la ciudad moderna [...] son como topos que andan por encima de la tierra" (p. 67). En El hombre perdido todo es metáfora, metáfora de la condición humana y sus implacables circunstancias. Para expresarlas, la ciudad laberíntica se nos antoja un significante con un alto grado de eficacia.

En otros relatos el papel del entorno urbano, sin dejar de aportar al universo de ficción alusiones a la filosofía ramoniana de la existencia, se liga más a lugares "reales". El caballero del hongo gris despliega toda una serie de ellos, dado que su protagonista viaja sin tregua por Europa: París, Lisboa, Marsella, Berna, Génova o Roma perfilan estaciones de una peregrinación que tiene su razón de ser en las estafas características de un hombre del día identificado por su sombrero: "El hongo gris llevaba a su cabeza ideas de elegancia y seguridades en el porvenir como si se hubiese puesto el cerebro de la época, el mejor cedazo de sus gustos y querencias". ${ }^{127}$ En un par de momentos, ciudad y novela se presentan relacionadas por el escritor, pues se alude a que Lisboa entraña "la ciudad moderna y novelesca" (p. 76) y a Marsella se la nombra "la ciudad novelística" (p. 142). Ramón tuvo por oficio el de espectador-cronista, a veces narrador, de los tiempos modernos, que se canalizaban a través de las grandes urbes; en consecuencia, como el personaje principal de El caballero del hongo gris, hubiera podido ostentar el título de "senador por derecho propio de las ciudades" (p. 125), sobre todo de dos ciudades: París, que es el punto en que Leonardo halla su bombín y segunda capital de la geografía del literato, y Madrid.

Ambas vertebran la mejor "construcción" novelesca de Gómez de la Serna, que además se inserta en un subgénero radicalmente urbano. Conviene detenernos con más detalle en esta obra maestra y piedra angular en la invención ramoniana de su Metrópolis. El Chalet de las Rosas ${ }^{128}$ es el relato "grande" de Ramón más próximo al género de la novela criminal, pero se publica en un periodo en que, a través de las versiones de obras foráneas y el surgimiento de series especializadas, este tipo de narraciones apenas si está sentando las bases para su ulterior desarrollo en España. ${ }^{129}$ En todo caso,

127 El caballero del hongo gris (1928). Barcelona: Salvat, 1970; 32. A esta edición pertenecen las páginas después de las citas.

${ }^{128}$ El Chalet de las Rosas (Novela grande). Valencia: Editorial Sempere, 1923. Todas las citas de la novela remiten a esta edición.

129 Vid. Valles Calatrava, J. R. La novela criminal española. Granada: Universidad, 1991; 94-5. 
estamos ante una versión muy personal del hecho delictivo, que une elementos del universo personal ramoniano, amor-sexo y muerte básicamente, con las fechorías del asesino múltiple de mujeres Henri-Désiré Landru, que desarrolló sus actividades en los años posteriores a la Gran Guerra. ${ }^{130}$ Así pues, puede decirse que con El Chalet de las Rosas nos hallamos ante una versión actualizada del tipo de textos conocido como "causas célebres", cuyo origen puede situarse hacia 1738 en la obra de François Gayot Causes célèbres et intéressants avec les jugements qui les ont decidées, momento en que empieza un progresivo interés social por lo criminal. ${ }^{131}$

Ahora bien, la peculiaridad del caso Landru, quien consiguió "hacer desaparecer" literalmente a sus víctimas y murió sin aceptar su culpa, al ser traspasada al mundo de la ficción por Gómez de la Serna, impide que se encasille la novela simplemente dentro del género policíaco. En efecto, Roberto Gascón, el héroe de El Chalet, sí confiesa a última hora sus crímenes y sí se encuentran los restos de varias mujeres que visitaron su casa, como quizá requería la justicia poética o la propia percepción de los hechos que motivaron el libro por parte del autor; pero existen indicios, como en su modelo francés, de que las muertas pudieron ser más. El lector halla en sus páginas incoherencias premeditadas, olvidos, confusiones, sospechas, es decir, un laberinto que responde a la naturaleza de la modernidad, y todo ello sin que el escritor proporcione una salida fiable, más que nada porque el narrador, como veremos, es el principal cómplice del asesino. De ahí la vigencia de El Chalet de las Rosas, un relato interactivo en el que por fuerza el receptor se ve involucrado y termina por ser el detective definitivo en busca de alguna ilusoria certeza. ${ }^{132}$

La complejidad de este artefacto típicamente urbano, y desde luego vanguardista, descansa de manera evidente sobre la figura de Roberto Gascón. No vale la pena detenernos ahora en el problema de hasta qué punto se trata de un personaje en clave, con Landru como referente inequívoco, pues comparten desde la apariencia física, calva y barba negra y espesa, hasta su tendencia a la teatralidad. Junto a ello, Gascón resulta una criatura singular entre los personajes ramonianos. ${ }^{133}$ Las marcas más llamativas de su caracte-

130 Cfr. Masson, R. "La mortelle romance de M. Landru. 1919-1921", en VV. AA., Les années folles, París, Denoël, 1956; 45-108.

131 Vid. Valles Calatrava, J. R. La novela criminal: Almería: Instituto de Estudios Almerienses, 1990; 49.

132 Vid. Serrano Asenjo, J.E. Ramón y el arte de matar (El crimen en las novelas de Gómez de la Serna), Granada: La General, 1992; 235-325.

${ }^{133}$ Rey Briones, Ob. cit., p. 120 
rización son la cortesía, la voluptuosidad, ${ }^{134}$ la pereza y el que se trate de un hombre de acción y de negocios, componentes que ayudan a explicar un tanto sus andanzas de ladrón y homicida sensual. Es un eficaz seductor y matador de mujeres, pero no tan hábil al querer ocultar las pruebas del delito, como puede comprobarse repetidamente durante el proceso (pp. 224-34), a pesar de que mucho antes se insista en que se deshace de toda pertenencia de sus víctimas (pp. 23-4, 69). Como fugitivo, Gascón empieza a evidenciar sus flaquezas.

$Y$ es que en este barba azul de nuevo cuño existen recovecos menos evidentes, pero esenciales dentro de su trayectoria, que lo perfilan como un representante aventajado de la edad contemporánea ${ }^{135}$ y permiten situarlo muy próximo a algunas preocupaciones de Gómez de la Serna. ${ }^{136}$ En él es compatible la acción con abundantes meditaciones sobre la vida cotidiana, el amor, la justicia o la muerte, pues con Gascón nos encontramos ante un solitario en continua charla consigo mismo, en otras palabras, un aventurero teorizador, tan reflexivo como corresponde a un héroe "modernista". 137 Excepcionalmente, tan sólo por un tiempo, puede enamorarse (p. 187 ss.), peripecia que, en alguien que viene orientando su ternura hacia las cosas, señala el comienzo del fin. Puede comprobarse cómo la captura del protagonista va ligada a su pasión por la secuestrada del judío polonés Kroztia. A la postre, amar, el intento de romper la soledad, le acarrea la muerte.

El hombre solo tiene miedo a que lo apresen, pero también a que en el proceso se demuestre que ha matado a quien él cree que no ha matado. Sin embargo, se ha de hacer constar acto seguido que Gascón no es de fiar ni siquiera en su fuero interno, en principio, porque olvida con extrema facilidad. Poco a poco, este héroe, que en la primera parte de la novela se muestra inmodesto, muy orgulloso de sí y con atisbos de soberbia, manifiesta una clara inseguridad ante el mundo. En definitiva, el lector del relato no ha de

${ }^{134}$ Mazzetti Gardiol, R. Ramón Gómez de la Serna, Nueva York, Twayne, 1974; 59. Para el análisis de este componente de las novelas del escritor, vid. F. López-Criado, El erotismo en la novelística ramoniana, Madrid, Fundamentos, 1988.

135 Cfr. Entrambasaguas, J. de Las mejores novelas contemporáneas. Tomo VIII (19301934). Barcelona: Planeta, 1970 [con la colaboración de M. P. Palomo]; 1.046.

136 Nora, E. G. de. La novela española contemporánea (1927-1939), Madrid, Gredos, $1973 ; 118$.

137 Vid. Bradbury, M. El mundo moderno. Diez grandes escritores, Barcelona, Edhasa, 1990 ( $1^{\text {a }}$ ed. en inglés en 1988), 40; o Hutcheon, L. The Politics of Postmodernism. Londres y Nueva York: Routledge, 1989; 27. 
perder de vista que miente como habla, que recomienda a su único amigo que no sea sincero nunca, justo antes de confesar en el juicio con pretendida sinceridad, y que, a esas alturas de su historia (p. 256), ya ha dado muestras de que no es capaz de dar cuenta de sus pensamientos y acciones (pp. 235-6). El héroe contemporáneo resulta grotesco en su intensa debilidad, que se incrementa hasta desembocar en imágenes propias del esperpento valleinclanesco y así Gascón es "fantoche trágico", "polichinela tendencioso", "pelele verdugo" o "monigote arruinado" (p. 249).

A continuación, hay que hacer referencia a las mujeres que se van mezclando con la carrera criminal de nuestro hombre y al respecto lo primero que destaca en el tratamiento de tan nutrido grupo es la misoginia, ${ }^{138}$ sin que baste como compensación el que en sus últimas declaraciones don Roberto escriba: "La mujer es el mejor consuelo del hombre, algo así como el algodón en rama para sus heridas" (p. 264), una curiosa mezcla de cinismo y palinodia, que podría justificar el terror producido por su próxima su ejecución. Las damas que se relacionan con el protagonista pueden ser víctimas o "resucitadas". Y dentro del primer apartado cabe distinguir las muertas confirmadas, tres, de las posibles, otras tantas. El retrato de las señoras de las que, sin lugar a dudas, se desprende Gascón es fácilmente comprensible teniendo en cuenta las intenciones del villano: maduras, solas y con dinero.

Algo más hay que decir de las posibles asesinadas. Al investigar la policía el curriculum homicida del personaje, varios detalles apuntan, como se advirtió arriba, a que pudo ser más amplio de lo que el lector de El Chalet de las Rosas pensaba. Un nombre apuntado en sus «carnets», "Rosaura" (p. 225); un pañuelo con las iniciales "L. T." (p. 228) y una tal "Genoveva", que parece ser la que más le compromete, a pesar de que Ramón no aclara bien el porqué, esas tres posibilidades son aludidas como "falsas asesinadas" (p. 233), pero el libro juega a confundir. No en vano en la segunda parte hay pistas suficientes para pensar en cuatro (p. 179) o cinco muertas (p. 186), cifras dispares que seguirían sin resolver el enigma. Por ahora, conviene limitarnos a hacer constar que no nos hallamos ante burdos descuidos del autor o excesivas suspicacias de los agentes del orden. El personaje criminal, tan lleno de zonas oscuras; el propio narrador-cómplice y el tratamiento del tiempo, muy poco específico, con vacíos no justificados, son elementos que coadyuvan a crear el misterio.

138 Martínez del Portal, M. "Estudio preliminar", en R. Gómez de la Serna, La Quinta de Palmyra. El Chalet de las Rosas. Barcelona: Bruguera, 1968, 9-28; 23. 
Menos incógnitas se esconden tras las "resucitadas" que se citaban hace un instante. Roberto Gascón no sólo hace desaparecer a ese número indeterminado de víctimas, sino que, llevado por las circunstancias de su vida delictiva, decide resucitar a dos mujeres. Cuando descubre que Dorotea Mayel, ya enterrada en su jardín, ha heredado una gran suma de dinero (p. 129), consigue que la nueva inquilina de la casa, Amanda, la sustituya con los papeles de la difunta, que no habían desaparecido tan radicalmente como hubiésemos esperado del profesional experto que Gascón nos hace creer que es. Mas don Roberto deja mucho que desear como resucitador y Amanda acabará por delatarle, esto es, pone en marcha el mecanismo que lleva a la muerte del interesado. Pero hay una experiencia más en este sentido, bien que metafórica. Cuando se halla en poder de la ley, el héroe piensa que puede ayudarle el descubrir que Kroztia mantiene secuestrada a una muchacha en su domicilio. En su decisión interviene el cálculo, no el presunto amor que sintió por la joven. Sea como fuere, él la "devuelve a la vida", mas no consigue ningún beneficio, sino que ella corrobore de la forma más fehaciente su caída al verle durante el juicio como "el hombrecito desgraciado y sombrío" (p. 254).

Pero este repertorio de personajes no puede prescindir de algunos otros de diversa trascendencia. Son imprescindibles en la trama Fernando Rojas, el amigo íntimo de Gascón, con dos apariciones distantes entre sí (pp. 35 y 255), y el judío polaco, con quien comparte el protagonista abundantes tardes y noches a lo largo de una temporada. La función de Rojas en su primera salida no sólo consiste en inquietar a don Roberto, al introducirse en su domicilio-cementerio, donde los varones tienen vedado el acceso, sino ayudar mínimamente a localizar el Chalet de las Rosas en Ciudad Lineal como se verá después. La segunda intervención todavía es más importante. Contribuye a establecer el tiempo que dura la acción y actúa como detonante para que el asesino confiese. En cuanto a Kroztia, nuestro matador únicamente se franquea con él, sin que los lectores sepamos los detalles, antes de dicha confesión final. El judío es un compinche, cuyo delito aquilata el alcance de las actividades de Gascón. El se siente inferior a "aquel hombre capaz de algo más que de matar, porque matar se mata de una vez y casi se olvida uno de ello, mientras que secuestrar es matar todos los días y tener el crimen presente a todas horas" (p. 181); pero, además, supone un intermediario para que don Roberto conozca a la secuestrada, con las nefastas consecuencias que se derivarán de ello.

Por fin, cabe mencionar varias figuras muy de segundo orden, pero que Gómez de la Serna esboza vívidamente con unos pocos trazos. Entre ellas, destacan el admirador de Aurelia, ciegamente enamorado, que adelanta la 
ejecución de la mujer que le fascinó al seguirla y percatarse de ello Gascón, a la vez que anticipa rasgos del criminal cuando el afecto por la secuestrada le desequilibre (p. 81 ss.); la prostituta parisina que se parece a la misma Aurelia, ejerce en un barrio decente y recibe por las tardes (p. $148 \mathrm{ss}$.); o el bobalicón novio de la mencionada Genoveva, que visita a su presunto asesino en la cárcel y sale de allí perplejo a causa de la extrema educación y cortesía del reo (pp. 234-5).

Al aludir al papel que desempeña el narrador en El Chalet de las Rosas quizá no sea descabellado considerarlo como una suerte de personaje más, omnipresente y capital en los rumbos del relato. En cualquier caso, la mayoría de sus matices se manifiestan ya desde el capítulo inicial. De entrada, sorprende al receptor el hecho de que la voz que cuenta la historia a menudo desempeñe su función de un modo harto impreciso: "Gascón iba con su especie de nueva esposa", "Ciudad Lineal tenía ese aspecto de cementerio de vivos" (p. 5); incluso con dudas: "Mira qué huevos más grandes -decía ella y probablemente entraban en los sitios en que más suculento era lo que les había admirado" (p. 6, subrayados míos). Se trata de un narrador bien distinto del omnisciente que caracteriza los relatos tradicionales. Aquí no lo sabe todo, y si es así, calla parte de su información. Más todavía, al margen de que en algún momento intente hacer gala de sinceridad, como por ejemplo: "Hay que confesar que, aun siendo un hombre sereno, don Roberto se llevó un susto terrible" (p. 17), el narrador puede mentir. De tan inquietante seña de identidad se nos avisa desde el principio, cuando después de llamar repetidamente a Matilde "esposa" de Gascón, sabemos que no están casados. No se trata de un detalle baladí en una novela como ésta, con un juego de ocultaciones tan calculado y significativo.

Conviene relacionar con lo anterior un rasgo del estilo ramoniano que la crítica ha comentado reiteradamente, a saber, la proliferación de greguerías en toda su obra y, por tanto, en sus narraciones. Simplificando mucho una cuestión que en los últimos años ha recibido aportes críticos fundamentales, puede decirse que se trata de un metaforizar inacabable por parte de Ramón. Nada resulta ser lo que parece simplemente, sino que toda cosa remite a otra: "Era triste como un canalillo, un canalillo de casas se entiende. Parecía las dos filas de gentes que se forman en los caminos para ver pasar la procesión. Dos filas de casas a lo largo del camino solitario" (p. 9). Con frecuencia, este continuo desplazamiento de identidades, que obviamente contribuye a hacer confusa la sucesión de los acontecimientos, lastra en exceso las novelas de Gómez de la Serna. Ahora bien, en nuestra historia policíaca, en la que los hechos acaban por sumirse en una suerte de nebulosa que desfigura los lími- 
tes entre la verdad y la mentira, esta faceta del narrador característico de los relatos ramonianos no parece una rémora, sino un componente destacado para fundar la incógnita.

El narrador participa en la historia que transmite de otras maneras, como confirma el empleo del diminutivo, con evidente valor de afectividad, en algunos pasajes: "parecía que incitaba y empujaba con sus panzuditos muslos a la persona que le miraba" (p. 8). Por ello, no extrañará la serie de personificaciones que recorre El Chalet, texto con una cierta carga mágica ("La lámpara del comedor se podría decir que acogía el crimen con cautela", pp. 156), y no estará de más recordar la tarea de protector de las cosas que se asignó Ramón, corroborada párrafos atrás respecto a la Ciudad. En fin, como balance de la actuación del narrador en el capítulo que abre el libro podemos señalar que es tendencioso, con intervenciones constantes a fin de conducir la atención del lector, pero lo hace interesadamente, despistando en algún caso. Se debe desconfiar de él, porque eso es lo que pretende: propiciar incertidumbre.

En el resto de El Chalet de las Rosas la figura que nos ocupa ofrece dos novedades importantes. Una consiste en que el narrador puede anticipar el porvenir: "no hay nada que haga descansar como el desenlace, iy qué desenlace!, un desenlace que se le ofrecía lleno de curiosidades, de coincidencias, de sorpresas" (p. 208). Esta vaga profecía al término de la segunda parte sirve para crear expectativas de lectura, es decir, se intenta mantener la atención de los receptores en un momento, el de la captura del facineroso, en que dicha atención podría verse mermada. Algo similar ocurrió al comienzo de esa parte, cuando Amanda y Gascón llegaban a París: "Ahora comienza la trama interesante de estas vidas" (p. 133). Las fronteras entre los tres tramos de la novela quedan subrayadas al encarecer el interés de la historia la voz que la cuenta. Otras anticipaciones de menor alcance señalan el desastrado final de don Roberto, con el que llegamos a la segunda novedad aludida. Al cerrar la obra, el narrador se vale de la primera persona, aunque sea en plural, para incorporarse explícitamente al texto y hacer patente su manipulación de los pulsos del mismo: "No es cosa de que presenciemos la ejecución./ Dejémosle morir a solas con su vergüenza y su miedo último. ¡Adiós, don Roberto!" (p. 265).

Esta somera referencia a la persona que narra El Chalet de las Rosas ha de llamar la atención sobre una peculiaridad más de esta obra maestra ramoniana. Repetidamente el narrador que se acaba de presentar cuenta la historia desde los personajes, sobre todo desde Roberto Gascón, pero también desde otros. Pues bien, la comunidad entre el narrador y el asesino es tal, que habrá 
pasajes en que no sea posible discernir a ciencia cierta qué corresponde a uno y a otro. En conclusión, no hay un único punto de vista en la novela, sino todo un rompecabezas de ellos, de forma que no existe una única realidad, más bien cabe hablar de mundos simultáneos, con zonas comunes, pero no necesariamente idénticas.

Los misterios de Madrid y París que sugiere El Chalet tienen otro pilar básico en el tratamiento que se da al tiempo, un aspecto generalmente descuidado por Ramón en sus novelas. ${ }^{139}$ La duración de los hechos que se relatan puede establecerse en algo más de dos años y medio, como mínimo, y no es posible lograr mayor concreción. Se precisa mejor el transcurrir de los meses en Madrid que en París, donde la falta de pistas sobre la vida de los fugitivos no sólo afecta al lugar de la urbe en que se establecen, sino también al tiempo que pasan en ella. Ahora bien, conviene tener en cuenta que a Gómez de la Serna no le interesa dar noticia exacta de las andanzas de Gascón. El curioso lector puede comprobar lo difícil que es distribuir los acontecimientos de la historia desde el encuentro con el amigo hasta el juicio que se celebra dos años después. A partir del primer jalón, Gascón vive seis meses más con Dorotea (p. 39) y en el año y medio restante ha de conocer y matar a Aurelia, y él se queja de cómo la belleza de ésta hace que se retrase su muerte (p. 79); ha de conocer a Amanda, hartarse de ella (p. 125), conseguir que suplante a Dorotea para cobrar la herencia y huir ambos a París, con todas las peripecias que allí acaecen; por fin, llega el proceso, de cuya larga duración se queja don Roberto (p. 229). A la postre, este desinterés permite que el rastro de Gascón resulte bastante difuso.

Pero además el autor permite que sus receptores puedan pensar que lo que cuenta no es toda la historia criminal del héroe. Repárese en la frase: "Estaba viviendo de nuevo la vida de soltero otra temporada" (p. 23). Si el narrador no miente de nuevo, es lícito deducir que ha habido alguna temporada previa y no se pierda de vista que los hechos que conducen a esta "otra", dadas las relaciones de Gascón con las mujeres, son un asesinato. En El Chalet no encontramos una clara continuidad en la información que se nos facilita del personaje central, ${ }^{140}$ lo que posibilita la presencia de "tiempos muertos" en la obra. Por tales entiendo esos momentos de duración indefinida en que no se halla ante los ojos del público y en los que puede realizar actos pertinentes para el curso de la novela, esto es, seducir y matar. En todo

139 Vid. Rey Briones, ob. cit., p. 58.

140 Cfr. Sheppard, R. "The crisis of language", en Bradbury y McFarlane, eds., ob cit., $323-36 ; 327$. 
caso, es obvio que considerar la existencia de esas zonas en la temporalidad del libro no sólo se permite con el citado modo, demasiado laxo, de fijar la cronología de los hechos, sino que es una operación inducida por las desapariciones de mujeres que se atribuyen a un homicida tan olvidadizo y poco riguroso en el inventario de sus fechorías como el mismo narrador.

Más que reparar en el desarrollo lineal del tiempo, vale decir el tiempo que avanza y destruye, a Gómez de la Serna le importan los ciclos temporales, el tiempo que vuelve, principalmente la alternancia de los días y las noches, que van a ir vinculándose con la muerte artificial. La mañana tiene muy escasa presencia en $\mathrm{El}$ Chalet, con una excepción realmente llamativa y aislada del resto de la trama, pues supone un recuerdo de la infancia del asesino sin más alcance que incluir en el discurso algunas greguerías (p. 95). En cambio, en la tarde se concentra el mayor número de acciones. De entrada, ella sugiere el crimen, da la señal para cometerlo, en definitiva, influye sobre él (p. 107), a veces aliada con el lugar: "he sentido la especial tentación a la despedida que llega con el atardecido a aquel paraje" (p. 260); pero a su vez, la muerte violenta otorga determinados rasgos a esta parte del día: "Lo que da ese gracioso escalofrío a la tarde es la actuación del crimen impune sobre las cosas" (p. 143). Más aún, trances determinantes en el curso de los acontecimientos suceden entonces: la consulta de Amanda con la adivina, que le avisa del gran peligro que es Gascón (p. 203); o el descubrimiento de los cadáveres en el jardín de las rosas (p. 213). Peru incluso una hipótesis razonable de recepción de la historia se sitúa en esa obsesiva localización temporal: "sus crímenes, que son los cuentos de hombres para hombres en las tardes aburridas y confinadas" (p. 153).

En la noche se refugia la voluptuosidad, a la que la muerte dota de un talante especialmente intenso (pp. 43 y 77). Pero ante todo es el instante de las ejecuciones (pp. 13 y 47), pues la oscuridad permite el tipo de inhumación discreta que pretende Gascón. Sin embargo, la noche más relevante de El Chalet precede a la desaparición del propio don Roberto. El mismo tiempo de los crímenes resultará el tiempo que subraya la justicia poética: "Había pasado la noche de velatorio de sí mismo que es la noche en capilla" (p. 264). Dos rasgos comporta dicho periodo: es larga y grave. Con él asistimos al último desánimo del protagonista, aunque sólo sea al pensar en los que en semejante circunstancia quedaron con el pelo blanco e independientemente de que, por su calvicie, tal contingencia sea improbable. ${ }^{141}$ Por último, llega

${ }^{141}$ Cfr. Yaquito, "el sentenciado a muerte universal", en R. Gómez de la Serna, El hombre de alambre (Novela para armar) (Ed. de H. Charpentier Saitz). Londres: Tamesis, 1994; 43. 
el alba. Quien dedicara un libro al alba como Gómez de la Serna, en El Chalet de las Rosas únicamente insiste en ella al principio y al final de la obra. Como amenaza que se ha de evitar cuando Gascón entierra a la primera mujer que conocemos (p. 21), y como "alba fija del último viaje" (p. 263). El libro queda así enmarcado entre el delito y el pago que corresponde por tal transgresión, dirigidos ambos hacia un amanecer que, por esta vez, Ramón elude.

Queda por mencionar el último, pero no el menor, de los factores que colaboran en la creación de los enigmáticos crímenes del Landru español, se trata del espacio, es decir, básicamente la Ciudad Lineal ideada por el escritor, industrial y hombre de ciencia Arturo Soria y Mata (1844-1920). Soria propuso hacia 1894 la construcción de un ferrocarril-tranvía de circunvalación de Madrid, que habría de unir Fuencarral, Hortaleza, Canillas, Vicálvaro, Vallecas, Villaverde, Carabanchel y Pozuelo. Una consecuencia del mismo sería la creación de una ciudad a lo largo de sus vías en condiciones higiénicas y de baratura mejores que en el casco de la Villa. En los primeros años veinte, momento en que se han de localizar las tropelías de Gascón, el tramo entre las carreteras de Aragón y Francia, con una longitud de unos cinco kilómetros, suponía la primera barriada de la nueva ciudad. Para sugerir una hipótesis de localización del hotelito de don Roberto, contamos con el testimonio de Fernando Rojas en la primera parte. El quiere situarse acerca de la ubicación de la casa en la Ciudad Lineal, mientras que el asesino intenta despistarle: “-¿Así que esto cae al lado del Teatro, sino que un poco apartado de la línea general? (...) -No, -replicó súbito don Robertoesto cae mucho más abajo, a un paso de las Ventas" (p. 37). Esto es, si concedemos que al amigo le asistía alguna razón y tenemos en cuenta la situación del Teatro de Ciudad Lineal (1906-1922), podría apuntarse que el Chalet de las Rosas quizá estuviese para Ramón entre los actuales Barrio Blanco y Barrio del Salvador de la capital madrileña.

Sea como fuere, lo cierto es que los cambios de humor que sufre Gómez de la Serna en relación a Madrid ${ }^{142}$ se documentan también respecto al proyecto de Soria y Mata, que en 1920 le parece una "ciudad de geómetros, de aburridos de la vida, de suicidios... de los que buscan un rincón en que acabar su fracaso o su tesis". ${ }^{143}$ La Ciudad Lineal por entonces era un lugar bas-

142 Dennis, N. "Prólogo", en R. Gómez de la Serna, París (Ed. de N. Dennis). Valencia: Pre-textos, 1986, 7-69; 25.

143 Vid. Hoyle, A. "The Politics of a Hatless Revolutionary, Ramón Gómez de la Serna", en N. Glendinning (ed.), Studies in Modern Spanish Literature and Art presented to Helen F. Grant. Londres: Tamesis, 1972, 79-96; 85. 
tante solitario, ya que la población tan sólo tenía carácter temporal y se encontraba muy dispersa. Junto a ello, la lenta construcción de la barriada y el pobre alumbrado ${ }^{144}$ ayudan a entender por qué Ramón sitúa en sus desmontes el marco del crimen y, a la postre, el que el abogado del delincuente explique sus desatinos como "un fenómeno del sitio" (p. 257).

Por lo demás, la organización espacial de la novela ha sido cuidada con gran detalle por el escritor. Se contraponen los emplazamientos de la primera parte y la segunda. En la primera hallamos un macroespacio, la Ciudad Lineal nombrada, que es el lugar del delito, más preciso que el correspondiente de la parte dos, todo París, donde se establecen los personajes a la hora de la huida. Ambos son personificados, como era esperable en el universo animista sobre el que suele escribir Gómez de la Serna. En los espacios mayores sobresalen dos microespacios, que comparten el ser a la vez lugares de muerte y escondites: el chalet y la tienda de taxidermista, un lugar privado y otro público, que tienen sus centros respectivamente en el jardín y en el escaparate. Por fin, en el tercer tramo del libro tiene menos trascendencia el ambiente carcelario, perfectamente difuminado, que las alusiones a los parajes del comienzo del relato, entre las que destaca el esfuerzo teórico sobre Ciudad Lineal (p. 256 ss.) con el que el abogado aspira, en vano, a suavizar el castigo de su cliente.

El análisis de la geografía del crimen que se acaba de dibujar permite algunas consideraciones que sirven para apreciar los argumentos del letrado. Como se sugería arriba, las características del nuevo barrio, sobre todo su aislamiento y escasez de habitantes, facilitan las actividades de Gascón: "El silencio al margen de una gran ciudad (...) es el silencio en que se agacha y se oculta todo lo malo de la gran ciudad. Hay meditaciones de crimen en ese silencio arrabalero" (p. 12). Cometida la muerte violenta, el entorno se hace eco de la misma, pero no de un modo especial, repárese en que Ramón habla primero en términos generales: "Con cada crimen se encalma la naturaleza. El paisaje de Ciudad Lineal se sentía automnecer con el nuevo crimen" (p. 96). Lo que no admite duda es que con este personificado lugar, quintaesencia de las metrópolis que posibilitaron el surgimiento de las vanguardias, estamos ante un verdadero testigo de los negocios de don Roberto, en rigor, el único testigo.

Los componentes elementales del relato a los que se ha hecho referencia tienen como única razón de ser sus lazos con la muerte artificial, una obse-

144 Maure Rubio, M.A. La Ciudad Lineal de Arturo Soria. Madrid: Colegio Oficial de Arquitectos, $1991 ; 185$. 
sión que es rastreable en el conjunto de la obra de Gómez de la Serna, y no sólo narrativa. Lo que individualiza a la novela El Chalet de las Rosas en esa vertiente destacada de la escritura ramoniana es que, como resultado de la "causa célebre" que se encuentra en su raíz, en ella termina por importar menos el crimen real que los crímenes posibles de los que se habla en el proceso. Tales sospechas convierten lo que hubiera podido ser una mera novela de misterio en un documento inapreciable sobre las fronteras de la realidad y el factor subjetivo que entraña, ${ }^{145}$ algo que, a la postre, logra humanizar la mentira. Por eso mismo, el lector de El Chalet de las Rosas debe saber que se adentra en un callejón sin salida, en el que por fuerza ha de perderse; a cambio, durante unas páginas podrá disfrazarse de investigador privado a través de las soledades de una ciudad ideal. 